\title{
Sistem Keamanan Brankas Berbasis Kartu E-ktp
}

\author{
Ath Thaareq Mahesa, Hendar Rahmawan, Avan Rinharsah, SamsulAriffin \\ 1,2,3,4 S1 Rekayasa Sistem Komputer, Perguruan Tinggi STMIK ASIA MALANG \\ e-mail : ${ }^{[1]}$ aththaareq.mahesa@gmail.com, ${ }^{[2]}$ hendarsaka@gmail.com, ${ }^{[3]}$ avanrinharsah@gmail.com, ${ }^{[4]}$ samsul@asia.ac.id
}

\begin{abstract}
ABSTRAK - Brankas adalah suatu tempat yang disediakan untuk menyimpan suatu benda yang berharga seperti dokumen penting, perhiasan, uang dan barang berharga lainnya. Pada saat ini keamanan brankas masih menggunakan sistem penguncian semi otomatis yaitu dengan menggunakan kunci kombinasi. Penggunaan kunci kombinasi kurang efisien karena pengguna brankas mudah lupa pin dari kunci kombinasi brankas. Kunci kombinasi juga mudah dibobol oleh pencuri. Saat ini penggunaan teknologi RFID (Radio Frequency Identification) di Indonesia mulai berkembang salah satunya kartu e-ktp yang sudah terdapat chip RFID tetapi untuk pemanfaatan masih kurang. Sistem kerja dari alat ini jika ingin membuka pintu brankas harus melakukan tapping menggunakan kartu e-ktp yang sudah terdaftar pada sistem keamanan brankas jika saat tapping sukses maka dari sistem keamanan akan menapilkan informasi di LCD dan mengirim informasi ke database yang sudah dibuat lalu ke aplikasi smartphone sebagai pengaman kedua, memanfaatkan teknologi Internet Of Things jika informasi dari smartphone disetujui maka pintu brankas akan terbuka dan aplikasi pada smartphone sebagai monitoring kondisi brankas jika akan terjadi pembobolan maka dari alat sistem keamanan brankas mengirim informasi ke aplikasi smartphone. Dan jika saat melakukan tapping kartu e-ktp yang tidak terdaftar di sistem keamanan maka pintu tidak akan terbuka.
\end{abstract}

Kata Kunci: Rfid MFRC522, Nodemcu, E-ktp

ABSTRACT_Safes are a place reserved for storing a valuable object such as important documents, jewellery, money and other valuables. At this time the security of the safe still uses a semi-automatic locking system that is by using combination locks. The use of combination locks is less efficient because users safe forget the pin of the combination lock safe. Combination locks are also easy in thieves. Nowadays, the use of RFID (Radio Frequency Identification) technology in Indonesia began to grow one of the e-ktp card that already contained RFID chip but for utilization still less. Working system of this tool if you want to open the safe door should be tapping using the e-ktp card that has been registered in the security system safety if the time of tapping success then the security system will transmit the information on the LCD and send Information to the database that has been created and then to the smartphone application as a second security, utilizing Internet Of Things Technology If the information from the smartphone is approved then the safety door will open and the application on the smartphone as a monitoring Safety condition If there will be a breach then from the security system tools the safe send information to the smartphone application. And if when tapping the E-KTP card that is not registered in the security system, the door will not open.

Index Terms: Rfid MFRC522, nodemcu, E-ktp 


\section{PENDAHULUAN}

Pada saat ini keamanan brankas masih menggunakan sistem penguncian semi otomatis yaitu dengan menggunakan kunci kombinasi. Penggunaan kunci kombinasi kurang efisien karena pengguna brankas mudah lupa pin dari kunci kombinasi brankas. Kunci kombinasi juga mudah di bobol oleh pencuri dengan berkembangnya teknologi.

Sedangkan fungsi brankas sangat dibutuhkan bagi orang - orang yang memiliki barang atau dokumen yang sangat berharga supaya aman dan terjaga dari segala macam bahaya.

RFID merupakan teknologi yang mengunakaan gelombang radio yang dapat digunakan untuk mengidentifikasi suatu objek [4] RFID adalah suatu sistem yang dapat mentransmisikan dan menerima data dengan memanfaatkan gelombang radio, terdiri dari 2 bagian yaitu (tag) atau transponder dan reader [4]

Elektronik Kartu Tanda Penduduk saat ini hanya digunakan untuk pengurusan administrasi di pemerintahan, pengurusan izin dan sebagai tanda pengenal atau tanda penduduk warga indonesia. Sedangkan Elektronik Kartu Tanda Penduduk mempunyai fitur chip RFID yang masih kurang untuk memanfaatkan dari fitur pada Elektronik Kartu Tanda Penduduk . Fitur pada Elektronik Kartu Tanda Penduduk dapat digunakan sebagai RFID tag karena didalamnya terdapat chip yang menyimpan nomor ID unik, alat pengaman brankas memanfaatkan e-ktp sebagai kunci untuk membuka brankas RFID reader $13,56 \mathrm{MHz}$ digunakan untuk membaca nomor ID pada ektp.

Penelitian ini memiliki tujuan untuk menghasilkan suatu produk yang dapat mengoptimalisasi pengguanaan e-ktp. Selain itu untuk mengetahui cara untuk menghubungkan dari aplikasi yang sudah dibuat pada Android, Mikrocontroller, dan Brankas. Dan untuk mengetahui cara merancang pengaman brankas mengunakan e-ktp dan kontrol menggunakan smartphone berbasis Internet Of Things.

Dari latar belakang dan identifikasi masalah yang sudah diuraikan diatas, maka rumusan masalah dalam penelitian ini adalah bagaimana merancang, membuat, dan menguji prototipe sistem keamanan brankas menggunakan kartu RFID e-ktp.

\section{TINJAUAN PUSTAKA \\ Brankas}

Brankas adalah sebuah lemari atau kotak besi yang tahan terhadap api dan memiliki kegunaan utama yaitu sebagai pelindung barang - barang berharga anda dari berbagai macam bahaya yang terbuat dari besi baja yang sistem pengunciannya menggunakan kunci kombinasi [1].

\section{NodeMcu V3}

NodeMcu adalah sebuah board elektronik yang didalamnya sudah memiliki firmware dan hardware yang memiliki fitur WiFi. Menggunakan chip ESP8266 (ESP 12-E) dan mempunyai memori sebesar $128 \mathrm{~KB}$ serta mempunyai pin I/O sebanyak 10 pin terdiri 9 digital dan 1 analog serta mempunyai koneksi USB, jack listrik dan tombol reset. Pin - pin ini berisi semua yang diperlukan untuk mendukung mikrokontroler. Perancangan NodeMcu memudahkan peneliti dalam mapping pin serta mengetahui aspek dari microcontroller tersebut. Gambar NodeMcu V3 dapat dilihat pada gambar 1.

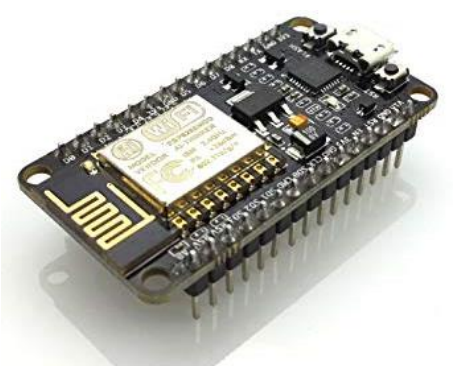

\section{Gambar 1. NodeMcu V3 RFID MFRC522}

Mifare MFRC522 RFID Reader Module adalah sebuah modul berbasis IC Philips MFRC522 yang dapat membaca RFID dengan penggunaan yang mudah dan harga yang murah, karena modul ini sudah berisi komponen-komponen yang diperlukan oleh MFRC522 untuk dapat bekerja. Modul ini dapat digunakan langsung oleh MCU dengan menggunakan interface SPI, dengan supply tegangan sebesar 3,3V. Perancangan RFID digunakan untuk melihat karakteristik dari RFID reader tipe kartu apa saja yang bisa, untuk memudahkan peneliti dalam perancangan desain alatnya nanti. Gambar 
dari RFID reader dapat dilihat pada gambar 2.

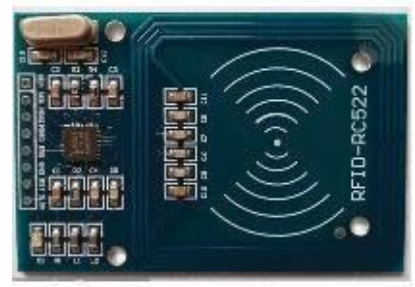

Gambar 2. RFID Reader

\section{Internet Of Things}

IoT adalah suatu konsep dimana memanfaatkan internet sebagai konektivitas dengan benda-benda lainnya. Diibaratkan dimana alat-alat bisa dikontrol dengan mengunakan smartphone untuk mematikan atau membuka pintu brankas atau menghidupkan alat lainnya.

\section{METODOLOGI PENELITIAN}

\section{Tahap Analisis}

Analisis pada penelitian ini terdiri dari atas dua bagian yaitu analisis kebutuhan bahan dan analisis kebutuhan alat. Penelitian ini bertujuan untuk menghasilkan sebuah sistem keamanan brankas berbasis kartu e-ktp, alat ini di proses menggunakan mikrokontroleresp 8266 (nodemcu) dan pemograman menggunakan bahasa $\mathrm{C}$. pada perangkat keras di supply mengunakan catu daya 5VDC untuk mikrokontroler,lcd,dan sensor dan catu daya 12VDC untuk solenoid. Pada akhir penelitian ini dilakukan tahap ujicoba untuk menilai apakah hasil dari penelitian ini sesuai dengan tujuan atau tidak.

\section{HASIL DAN PEMBAHASAN} Analisa Masalah

Potensi tindak kejahatan dapat terjadi pada sebuah brankas, pada saat ini sistem keamanan brankas masih menggunakan kunci kombinasi yang mudah dibobol di internet pun banyak tutorialnya. Dan jika terjadi pencurian pada umum nya brankas tidak adanya alat untuk mendeteksi kejadian saat pemilik sedang tidak berada ditempat. Bentuk alat pendeteksi pada umumnya berupa alarm yang tidak dapat memberi informasi kepada pemilik jika tidak berada ditempat. Pada sistem keamanan brankas yang di buat peneliti dapat memberitahu keadaan brankas ke pemilik brankas kapan dan dimana berada dengan menggunkan smartphone yang didukung dengan teknologi internet of things serta sebagai pengaman kedua pada brankas dan pada sistem keamanan brankas tidak menggunakan kunci kombinasi pada umumnya tettapi memanfaatkan chip RFID pada e-ktp sebagai kunci pada brankas dan chip RFID sangat sulit untuk diduplikasi. Model keamanan kunci konvensional pada umumnya digambarkan pada diagram sebagai berikut dapat dilihat pada gambar 3 .

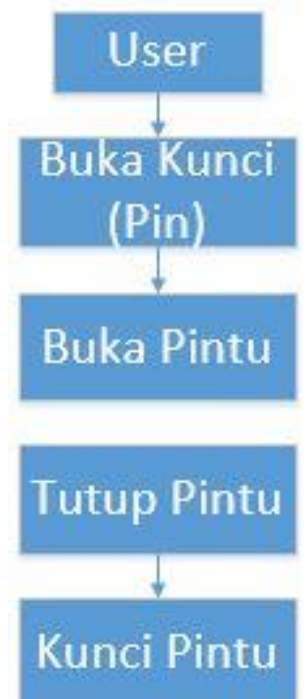

Gambar 3. Sistem Keamanan Brankas Konvesional

\section{Perancangan Sistem}

Dalam merancang sistem keamanan brankas berbasis kartu RFID e-ktp terbagi menjadi dua bagian yaitu perancangan perangkat keras (hardware) dan perangkat lunak (software).

Dalam sistem ini, Pertama kartu RFID akan ditempelkan pada RFID reader untuk 
pembacaan data pada kartu e-ktp. Setelah kartu e-ktp selesai dibaca, maka data ID kartu e-ktp tersebut akan diproses oleh NodeMcu V3, dan akan melihat ID kartu ektp tersebut, apakah kartu tersebut adalah kartu yang terdaftar pada sistem keamanan atau tidak. Jika kartu e-ktp tersebut adalah kartu e-ktp terdaftar, maka NodeMcu V3 akan mengirimkan informasi tersebut melalui database dan datanya disimpan dan dikirim ke aplikasi smartphone sebagai pengaman kedua, jika divalidasi setujui oleh aplikasi smartphone maka data terkirim ke databse dan mengirim ke NodeMcu untuk memperintahkan sinyal output untuk mengaktifkan rangkaian driver relay sehingga solenoid bisa aktif dan membuka pintu Brankas. Selain itu, NodeMcu V3 juga akan memerintahkan LCD untuk mengeluarkan berupa informasi seperti "Silahkan Tapping Kartu E-KTP", Status WiFi, dan status kondisi. Dan jika ID kartu e-ktp tidak terdaftar pada sistem keamanan maka pada LCD akan mengeluarkan sebuah informasi "Akses Ditolak". Digambarkan pada diagram sebagai berikut dapat dilihat pada gambar 4 .

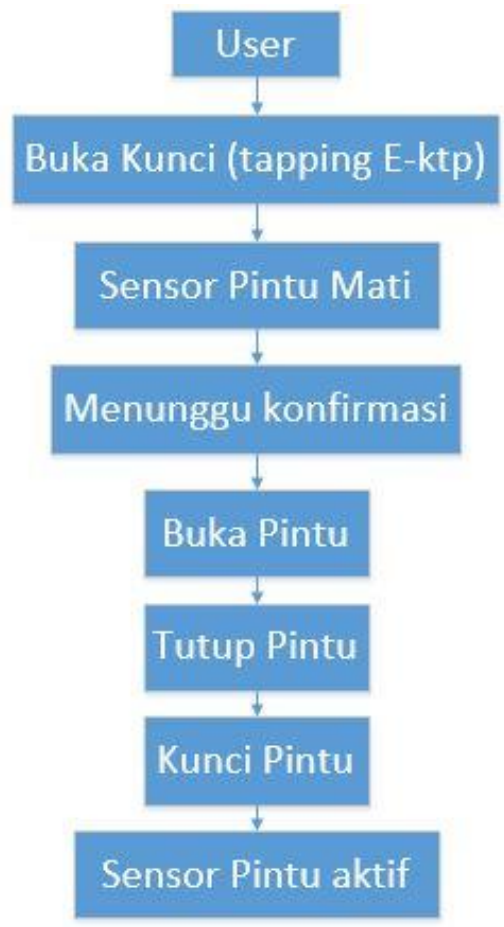

Gambar 4. Sistem Keamanan Brankas yang diusulkan

\section{Blok Diagram Alat}

Blok diagram alat akan berguna untuk mempermudah melihat hubungan antara subsitem yang satu dengan subsistem yang lain. Blok diagram alat dalam penelitian ini dapat dilihat pada gambar 5

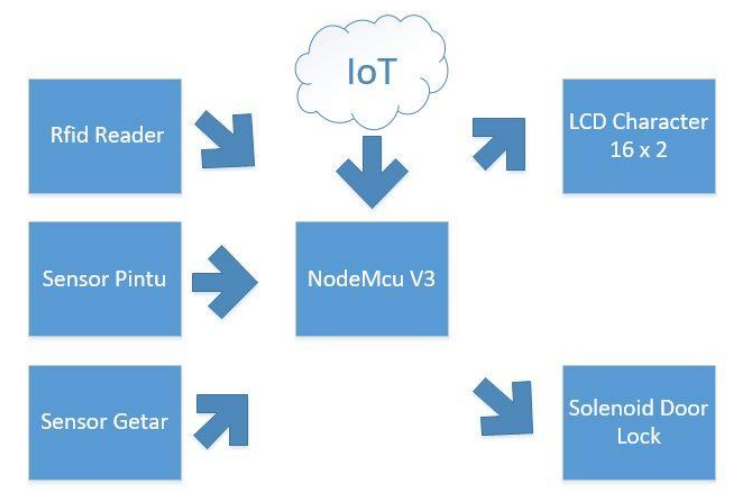

Gambar 5. Blok Diagram Sistem keamanan Brankas

Berdasarkan gambar 5, kita tahu bahwa terdapat tujuh subsistem yang terdapat dalam alat sistem keamanan brankas berbasis kartu rfid e-ktp, fungsi tujuh subsistem tersebut adalah sebagai berikut :

1. RFID Reader, fungsi dari subsistem ini adalah untuk membaca ID dan informasi yang ada pada suatu kartu RFID. Pada penelitian ini, RFID reader digunakan untuk membaca ID pada kartu e-ktp yang terdapat dalam kartu e-ktp yang digunakan sebagai kunci pada sistem keamanan brankas.

2. Sensor Pintu, fungsi dari subsistem ini adalah mengirim logika atau status ke mikrokontroler. Pada penelitian ini, digunakan untuk mengetahui kondisi saat pintu sedang tertutup atau terbuka yang informasinya akan ditampilkan pada LCD dan aplikasi smartphone.

3. Sensor Getar, fungsi dari subsistem ini adalah mengirim logika atau status ke mikrokontoler. Pada penelitian ini digunakan untuk mengetahui kondisi brankas jika terjadi pembobolan pada pintu brankas.

4. Internet of Things (IoT), fungsi dari subsistem ini adalah sebagai control atau monitoring yang memanfaaatkan sebuah konektivitas internet yang tersambung secara terus-menerus. Dalam penelitian ini, fungsi dari IoT adalah sebagai jalur komunikasi antara hardware dengan aplikasi mobile yang dijembatani dengan database.

5. NodeMcu, fungsi dari subsistem ini adalah sebagai memproses sekaligus sebagai konektivitas antara internet 
dengan hardware yang dilengkapi dengan WiFi. Di penelitian ini, tugas dari NodeMcu adalah sebagai memproses, memperintahkan suatu fungsi dari modul RFID reader, sensor pintu, sensor getar, komunikasi internet, LCD dan solenoid door lock

6. Solenoid, fungsi dari subsistem ini adalah sebagai aktuator. Dalam penelitian ini, solenoid digunakan untuk mengunci atau membuka kunci dari pintu brankas yang dikontrol dengan relay sebagai cut off aliran listrik, dikarenakan solenoid door lock akan terbuka jika diberi tegangan sebesar $12 \mathrm{~V}$.

Liquid Crystal Display (LCD), fungsi dari subsistem ini adalah untuk menyampaikan informasi status atau keadaan brankas seperti informasi silahkan tapping kartu e-ktp, Akses Sukses, Akses Gagal.

\section{Flowchart}

Flowchart digunakan untuk menuangkan algoritma yang digunakan oleh peneliti dalam penelitian ini, gambar flowchart dapat dilihat pada gambar 6

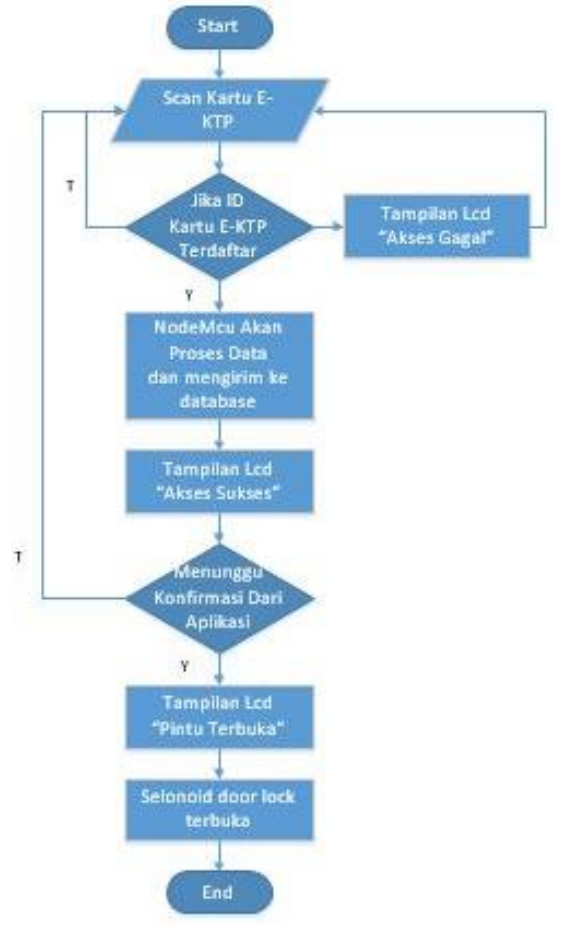

Gambar 6. Flowchart Alat
Dari gambar diatas dapat kita lihat bahwa saat RFID reader membaca ID kartu E-ktp, jika ID kartu E-ktp terdaftar maka akan muncul di LCD "Akses Sukses" dan ID tersebut akan diproses dan menunggu konfirmasi dari aplikasi yang sudah dibuat dan jika sudah di konfirmasi maka pintu akan terbuka dan sebaliknya jika ID tersebut tidak terdaftar akan muncul di LCD "Akses Gagal".

\section{Desain Alat}

Berikut ini adalah desain prototype dari keamanan brankas berbasis kartu RFID e$\mathrm{ktp}$, pada prototype ini dengan skala $50 \mathrm{~cm} \mathrm{x}$ $50 \mathrm{~cm}$ sebagai uji coba pada sistem keamanan brankas dan pada prototype ini menggunakan bahan plat besi setebal $3 \mathrm{~mm}$ berikut tampak dari desain alat.

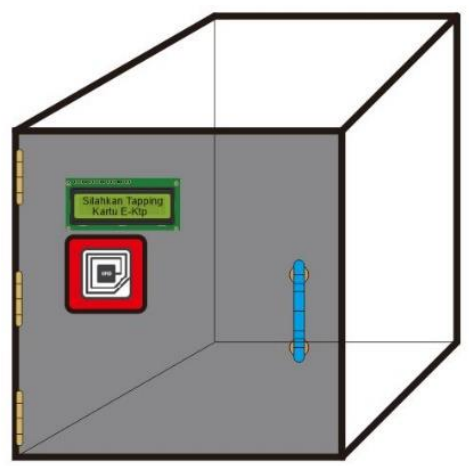

Gambar 7. Desain Alat Tampak Depan

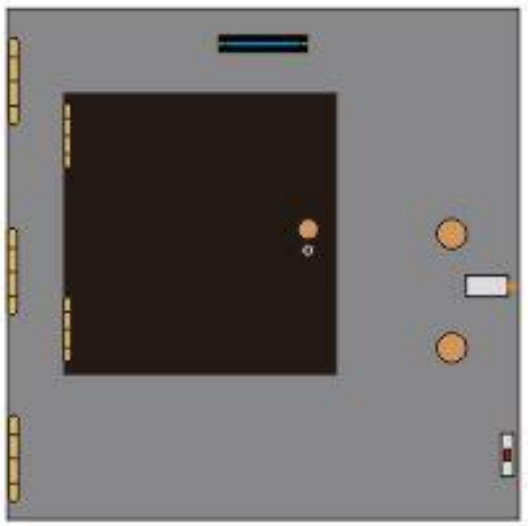

Gambar 8. Desain Alat Tampak Dalam Brankas

\section{Perancangan Hardware}

Peracangan hardware adalah 
perencanaan yang dilakukan untuk membuat beberapa perangkat keras agar bisa bekerja sesuai dengan yang diinginkan. Perencaaan hardware terdiri dari perancangan rangkaian elektronik dan perancangan mekanik.

\section{Perancangan Rangkaian}

Perancangan rangkaian elektronik berfungsi untuk menentukan subsistemsubsistem elektronik yang dibutuhkan untuk membuat penelitian ini berhasil. Rangkaian elektronik yang pada penelitian ini adalah terdiri dari rangkaian input, rangkaian pemroses dan rangkaian output. Pada rangkaian input menggunakan modul RFID, modul sensor pintu, modul sensor getar serta koneksi internet. Rangkaian pemroses menggunakan NodeMcu V3, sedangkan pada output menggunakan solenoid door lock sebagai kunci elektromagnetik, LCD character. Selain itu, ada rangkaian catu daya sebagai pemasok daya untuk setiap rangkaian dapat dilihat pada gambar 4.7.

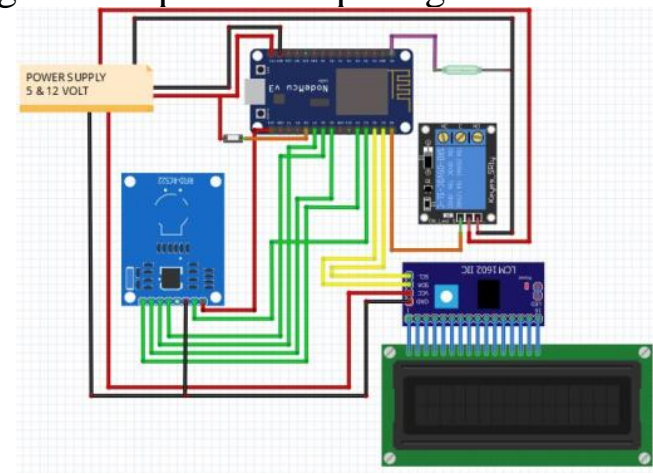

Gambar 9. Rancangan Rangkaian Alat Perancangan Catu Daya

Perancangan catu daya dibutuhkan karena, kita harus mendesain supaya catu daya yang kita rancangkan sesuai dengan kebutuhan sistem. Catu daya digunakan sebagai supply tegangan untuk semua rangkaian. Pada penelitian ini menggunakan dua rangkaian catu daya, yaitu catu daya 12VDC dan catu daya 5 VDC. Catu daya 12VDC digunakan untuk memberikan tegangan untuk

\section{Perancangan Mekanik}

Perencanaan perangkat mekanik ini bertujuan untuk implementasi alat dan aplikasi secara nyata dan real dari proses sistem pengendali yang berbentuk sebuah prototype, sehingga dapat dipahami dengan mudah dan jelas. Adapun perencanaannya adalah ukuran prototype brankas tidak boleh terlalu besar, dan uji seberapa kuat ketahanan pada alat brankas tersebut.

\section{Perancangan Program}

Perencanaan program bertujuan untuk menentukan algoritma alat secara program, dan perencanaan pin I/O pada nodemcu yang akan digunakan. Algoritma yang dimaksud adalah deskripsi kerja program yang akan mengendalikan sistem. Tabel perencanaan pin I/O yang akan digunakan dapat dilihat pada tabel 4.1, 4.2, 4.3, 4.4 dan 4.5.

\begin{tabular}{|l|l|l|}
\hline No & Pin RFID & Pin NodeMcu \\
\hline 1 & SDA & D4 \\
\hline 2 & SCK & D5 \\
\hline 3 & MOSI & D7 \\
\hline 4 & MISO & D6 \\
\hline 5 & IRQ & - \\
\hline 6 & GND & GND \\
\hline 7 & RST & D3 \\
\hline 8 & VCC & $3,3 \mathrm{~V}$ \\
\hline
\end{tabular}

Tabel 1. Pin I/O NodeMcu V3 dan Modul RFID Reader RC-522

\begin{tabular}{|l|l|l|}
\hline No & Pin LCD I2C & $\begin{array}{l}\text { Pin } \\
\text { NodeMcu }\end{array}$ \\
\hline 1 & SDA & D2 \\
\hline 2 & SCL & D1 \\
\hline 3 & GND & GND \\
\hline 4 & VCC & VCC \\
\hline
\end{tabular}

Tabel 2. Pin I/O NodeMcu dan LCD I2C

\begin{tabular}{|l|l|l|}
\hline No & $\begin{array}{l}\text { Pin Sensor } \\
\text { Getar }\end{array}$ & Pin NodeMcu \\
\hline 1 & DATA & A0 \\
\hline 2 & GND & GND \\
\hline 3 & VCC & VCC \\
\hline
\end{tabular}

Tabel 3. Pin I/O NodeMcu dan Sensor Getar Sw-40

\begin{tabular}{|l|l|l|}
\hline No & $\begin{array}{l}\text { Pin Sensor } \\
\text { Pintu }\end{array}$ & $\begin{array}{l}\text { Pin } \\
\text { NodeMcu }\end{array}$ \\
\hline 1 & DATA & D8 \\
\hline 2 & GND & GND \\
\hline
\end{tabular}

Tabel 4. Pin I/O NodeMcu dan Sensor Pintu

\begin{tabular}{|l|l|l|}
\hline No & Pin Solenoid & $\begin{array}{l}\text { Pin } \\
\text { NodeMcu }\end{array}$ \\
\hline 1 & DATA & D1 \\
\hline 2 & GND & GND \\
\hline 3 & VCC & VCC \\
\hline
\end{tabular}

Tabel 5. Pin I/O NodeMcu dan Solenoid

\section{Perancangan Program Aplikasi}

Perencanaan program aplikasi bertujuan untuk membuat agar aplikasi mempunyai 
user interface yang bagus dan memudahkan pemakai serta bisa berkomunikasi dengan alat sistem keamanan yang sudah di buat, pada aplikasi terdapat fungsi button ketika button door di klik maka membuka kunci pada pintu brankas yang sebagai keamanan kedua, fungsi button log out untuk keluar pada aplikasi dapat dilihat pada gambar 10 .

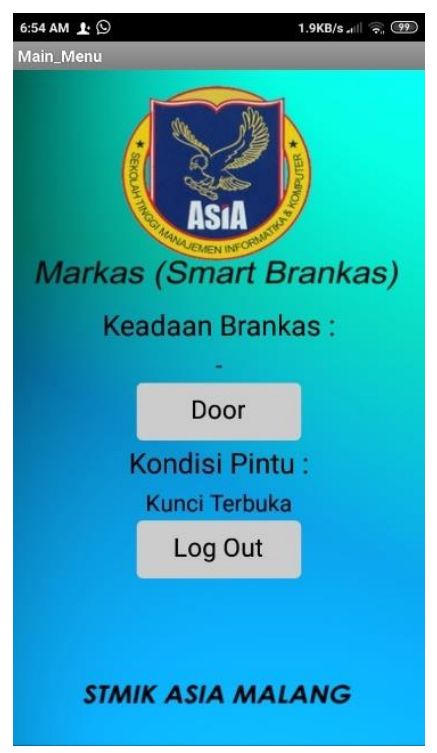

Gambar 10. User Interface Aplikasi

Keamanan Brankas

\section{Instrument Pengujian}

Instrumen yang digunakan pengujian alat sistem keamanan brankas berbasis kartu RFID e-ktp yaitu :

1. Untuk mengukur tegangan input dan output pada rangkaian, instrument peneliti menggunakan alat ukur multimeter digital. Multimeter digital dipilih kerena nilai yang dihasil kan lebih akurat dibandingkan dengan multimeter analog.

2. Untuk mengetahui jarak maksimal RFID Reader untuk pembacaan sinyal yang dikirim pada kartu e-ktp pada pengujian ini peneliti menggunakan penggaris dengan panjang $30 \mathrm{~cm}$. dan pengukuran dilakukan secara beberapa kali guna mengetahui jarak rata-rata pembacaan yang bisa di lakukan oleh RFID reader.
3. Untuk mengetahui koneksi pada alat sistem keamanan brankas dengan database dan aplikasi smartphone, pada pengujian ini dilakukan test koneksi dengan cara menghubungkan alat dengan internet.

4. Untuk mengetahui perbedaan hasil antara sistem keamanan brankas konvesional dengan sistem keamanan brankas berbasis kartu RFID e-ktp.

\section{Hasil Pengukuran Rangkaian Catu Daya}

Pengukuran tegangan pada rangkaian catu daya dilakukan agar dapat mengetahui berapa output tegangan yang keluar dari rangkaian driver relay, dan output tegangan yang keluar dari rangkaian catu daya ke NodeMcu. Hasil pengukuran tegangan di driver relay dan NodeMcu dapat dilihat pada tabel 6.

\begin{tabular}{|c|c|c|}
\hline No & $\begin{array}{c}\text { Output } \\
\text { Tegangan Catu } \\
\text { Daya }\end{array}$ & $\begin{array}{c}\text { Output } \\
\text { Tegangan } \\
\text { Catu Daya } \\
\text { NodeMcu }\end{array}$ \\
\hline 1 & $5,00 \mathrm{~V}$ & $4,99 \mathrm{~V}$ \\
\hline
\end{tabular}

Tabel 6. Hasil Pengukuran catu daya

\section{Hasil Pengukuran Tegangan Pada Solenoid}

Pengukuran tegangan pada solenoid dilakukan agar dapat mengetahui berapa tegangan yang dibutuhkan untuk mengaktifkan solenoid. Hasil pengukuran tegangan disolenoid dapat dilihat pada tabel 7.

\begin{tabular}{|l|l|l|}
\hline No & Alat & Pengukuran \\
\hline 1 & Solenoid & $12,2 \mathrm{~V}$ \\
\hline
\end{tabular}

Tabel 7. Hasil Pengukuran catu daya

\section{Pengujian Jarak Pembacaan RFID \\ Reader}

Dari beberapa kali percobaan yang sudah dilakukan oleh peneliti kepada RFID reader, maka peneliti mengambil kesimpulan bahwa jarak rata-rata antara RFID reader dan kartu RFID yang dapat diberikan agar RFID reader dapat bekerja dengan baik adalah 
kurang dari $13 \mathrm{~mm}$.

\section{Pengujian Komunikasi Alat Dengan Database}

Dari beberapa kali percobaan alat dapat berkomunikasi dengan database dan aplikasi smartphone dan waktu pengiriman data atau menerima data dari database tergantung kecepatan internet. Dari pengujian ini dapat dilihat pada tabel 8 .

\begin{tabular}{|c|c|c|}
\hline No & Pengujian & Hasil \\
\hline 1 & $\begin{array}{l}\text { Alat dapat } \\
\text { terkoneksi } \\
\text { dengan internet }\end{array}$ & $\begin{array}{l}\text { Sukses } \\
\text { ( } 2 \text { detik) }\end{array}$ \\
\hline 2 & $\begin{array}{l}\text { Alat dapat } \\
\text { mengirim data } \\
\text { sensor dan ID e- } \\
\text { ktp }\end{array}$ & $\begin{array}{l}\text { Sukses } \\
\text { ( } 2 \text { detik) }\end{array}$ \\
\hline 3 & $\begin{array}{lr}\text { Alat dapat } \\
\text { menerima data } \\
\text { sensor dan ID e- } \\
\text { ktp }\end{array}$ & $\begin{array}{l}\text { Sukses } \\
\text { (1 detik) }\end{array}$ \\
\hline 4 & $\begin{array}{l}\text { Aplikasi } \\
\text { smartphone dapat } \\
\text { terkoneksi ke } \\
\text { database }\end{array}$ & $\begin{array}{l}\text { Sukses } \\
\text { (1 detik) }\end{array}$ \\
\hline 5 & $\begin{array}{l}\text { Aplikasi dapat } \\
\text { mengirim } \\
\text { perintah ke alat } \\
\text { melalui database }\end{array}$ & $\begin{array}{l}\text { Sukses } \\
\text { ( } 2 \text { detik) }\end{array}$ \\
\hline
\end{tabular}

Tabel 8. Hasil Uji Coba Alat

\section{Hasil Alat}

Alat sistem keamanan brankas ini dibuat mengunkanan program bahasa $\mathrm{C}$ untuk membuat listing program ke mikrokontroler esp 8266 (nodemcu). Pengujian alat ini bekerja dengan cara tapping kartu e-ktp ke rfid reader yang terdapat pada alat dengan cara mendekatakan kartu e-ktp ke rfid reader dapat dilihat pada gambar 11 .

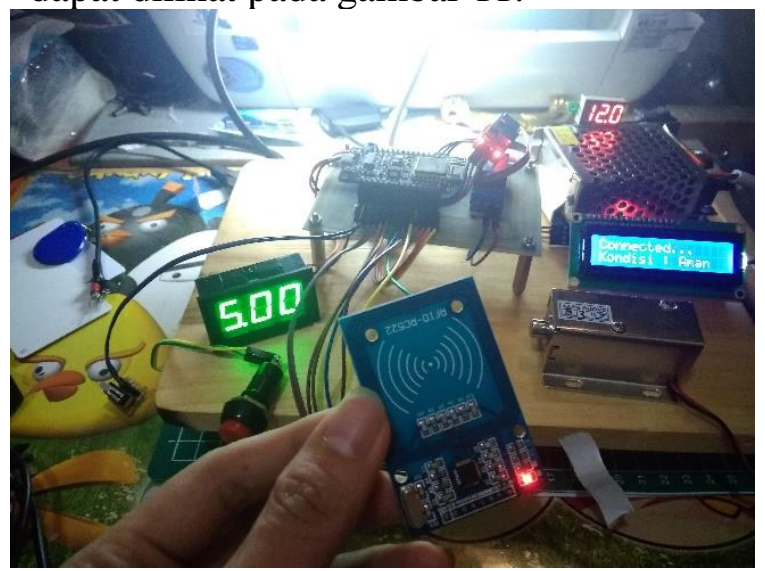

Gambar 11. Hasil Uji Coba Alat

\begin{tabular}{|c|c|c|c|}
\hline \multirow{3}{*}{ No } & \multirow{3}{*}{ Kondisi } & \multicolumn{2}{|c|}{ Mahesa,ath (2019) } \\
\hline & & & \\
\hline & & solenoid & Lcd \\
\hline 1 & Belum tapping & Off $(0 \mathrm{~V})$ & $\begin{array}{c}\text { On }(5 \\
\text { V) }\end{array}$ \\
\hline 2 & $\begin{array}{l}\text { Akses tapping } \\
\text { benar }\end{array}$ & $\begin{array}{c}\text { On }(12,2 \\
\text { V) }\end{array}$ & $\begin{array}{c}\text { On }(5 \\
\text { V) }\end{array}$ \\
\hline 3 & $\begin{array}{l}\text { Akses taping } \\
\text { salah }\end{array}$ & Off $(0 \mathrm{~V})$ & $\begin{array}{c}\text { On }(5 \\
\text { V) }\end{array}$ \\
\hline 4 & $\begin{array}{l}\text { Sensor pintu } \\
\text { tidak terdeteksi }\end{array}$ & $\begin{array}{c}\text { On }(12,2 \\
V)\end{array}$ & $\begin{array}{c}\text { On }(5 \\
\text { V) }\end{array}$ \\
\hline 5 & $\begin{array}{l}\text { Sensor pintu } \\
\text { terdeteksi }\end{array}$ & Off $(0 \mathrm{~V})$ & $\begin{array}{c}\text { On }(5 \\
\text { V) }\end{array}$ \\
\hline
\end{tabular}

Tabel 9. Hasil Ujicoba Alat

\begin{tabular}{|l|l|c|}
\hline No & \multicolumn{1}{|c|}{ Kondisi } & Port \\
\cline { 3 - 3 } 1 & $\begin{array}{l}\text { Button tidak } \\
\text { di klik }\end{array}$ & Off $(0 \mathrm{~V})$ \\
\hline 2 & Button di klik & On (12,2 V) \\
\hline
\end{tabular}

Tabel 10. Hasil Uji Coba Aplikasi

\begin{tabular}{|c|c|c|}
\hline No & Kondisi & Port \\
\cline { 3 - 3 } & Sensor Getar \\
\hline 1 & Ada getaran & On (5 V) \\
\hline 2 & $\begin{array}{c}\text { Tidak ada } \\
\text { getaran }\end{array}$ & Off (0 V) \\
\hline
\end{tabular}

Tabel 11. Hasil Uji Coba Sensor Getar

\section{KESIMPULAN DAN SARAN}

Setelah melakukan perencanaan dan pembuatan alat yang kemudian dilakukan pengujian, maka peneliti dapat mengambil kesimpulan sebagai berikut:

1. Pembacaan kartu e-ktp dapat dimanfaatkan sebagai pengaman pada brankas dan kartu e-ktp lebih efektif dikarena dibawa setiap hari dan sangat sulit untuk di palsukan atau di duplikasi.

2. Pada sistem keamanan sistem brankas yang dibuat oleh peneliti hasil lebih baik dikarenakan terdapat fiktur monitoring yang dapat dilihat pada aplikasi smartphone.

3. Jarak pembacaan kartu ke modul RFID READER dengan jarak maximal 13mm / $1,3 \mathrm{~cm}$.

4. Komunikasi dalam mengirim data ataupun menerima data tergantung dari kecepatan internet.

Peneliti mempunyai saran untuk mengatasi dan melengkapi beberapa 
kelemahan pada penelitian ini, saran tersebut diantaranya adalah:

1. Mengganti mekanisme kunci sehingga bisa dibuka dari luar saat sumber listrik tidak ada.

2. Menggunakan microcontroler pin yang lebih banyak supaya bisa menambah indikator seperti buzzer.

3. Pada box brankas masih menggunakan plat besi 3mm untuk ketahanan yang baik menggunakan bahan baku yang lebih kuat seperti besi baja.

\section{REFERENSI}

[1] “Brankas,"https://id.wikipedia.org/wi ki/Brankas (Diakses pada tanggal 18 Mei 2019).

[2] Datasheet RFID Reader/Writer Module MIFARE RC522 13.56MHz.http://www.alldatasheet.co $\mathrm{m} /$ view.jsp?Searchword=Mfrc522\% 20datasheet Diakses pada tanggal (21 Mei 2019).

[3] Gabriel, A. K. dan O. K. Boyinbode. 2011. The Place of Emerging RFID Technology in National Security and Develoment. International journal of Smart Home

[4] Saputro, Eko. 2016, Rancang Bangun Pengaman Pintu Otomatis Menggunakan E-Ktp Berbasis Mikrokontroler Atmega328 Semarang: Universitas Negeri Semarang. 